\title{
Short-Long R-R Sequence Induced Implantable Cardioverter Defibrillator Shock by Dislodged Lead Even Having Normal Interrogation Parameter
}

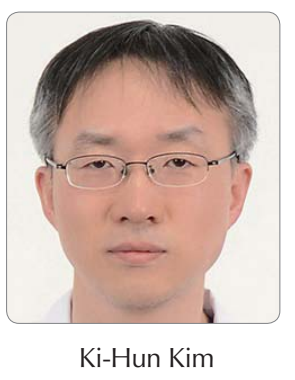

Ki-Hun Kim, MD, Sang-Hoon Seol, MD, Seunghwan Kim, MD, DongKie Kim, MD, Doo-Il Kim, MD

Haeundae Paik Hospital,

Department of Internal Medicine, Inje University College of Medicine, Busan, Korea

Received: February 13, 2018

Accepted: March 16, 2018

Correspondence: Sang-Hoon Seol, MD

Department of Medicine, Inje University College

of Medicine, Haundae Paik Hospital, 875

Haeundae-ro, Haeundae-gu, Busan, 48108,

Korea.

Tel: +82-51-797-3070, Fax: +82-51-797-3009

E-mail: hacemed@hanmail.net

Copyright (C) 2018 The Official Journal of Korean Heart Rhythm Society Editorial Board

\begin{abstract}
Inappropriate shocks from an implantable cardioverter defibrillator (ICD) can cause potentially dangerous ventricular arrhythmias and impaired quality of life. We describe a case in which a dislodged lead caused inappropriate ICD shocks through simultaneous sensing of atrial and ventricular signals. Interestingly, repeated shortlong R-R sequences were recorded, but ICD interrogation parameters were usually unchanged.
\end{abstract}

Key Words: - Defibrillators - Implantable - Lead

\section{Introduction}

Inappropriate shocks from an implantable cardioverter defibrillator (ICD) are of significant concern. We describe a case in which misreading of atrial signals as ventricular signals by a dislodged ventricular lead was the cause of inappropriate shocks. Confirmation of the lead location with immediate interrogation of the ICD event is essential for preventing inappropriate ICD shocks.

\section{Case}

A 59-year-old man with a history of dilated cardiomyopathy and severely impaired left ventricular function (left ventricular ejection fraction 25\%) experienced an episode of multiple ICD shocks. An ICD (St. Jude Medical, St. Paul, MN, USA) with a single ventricular lead had been implanted one month previously for primary prevention. The lead was positioned in the right ventricular (RV) apex with adequate slack, and there were no procedure-related complications. ICD programing was set as follows: single 8-pulse anti-tachycardia pacing (ATP) in the ventricular tachycardia zone (360-301 ms) or the ventricular fibrillation (VF) zone ( $\leq 300 \mathrm{~ms})$, both followed by ICD shocks of $25 \mathrm{~J}$, then $35 \mathrm{~J}$. Ventricular sensitivity was set at $0.5 \mathrm{mV}$, with decay delay $60 \mathrm{~ms}$, and duration of detection 12 beats. Postoperative and pre-discharge testing showed normal sensing, appropriate pacing parameters (sensed $\mathrm{R}$ wave amplitude of $11.7 \mathrm{mV}$, with pacing threshold $0.5 \mathrm{~V}$ at $0.5 \mathrm{~ms}$ and $\mathrm{RV}$ pacing impedance of $570 \mathrm{ohms}$ ), and stable lead position. He returned to the outpatient clinic 1 month later and the ICD parameters were still within normal range. However, 2 hours after the visit, he returned to the emergency room complaining of multiple ICD shocks without prodromal symptoms. During the ICD shocks, electrogram of each event showed the same pattern of repeated short-long R-R sequences, with misinterpretation of short- 
coupled $\mathrm{R}$ waves as a fibrillation rhythm. The fast and alternating R-R intervals provoked ATP, followed by ICD shock (Figure 1A). However, the ICD parameters were still within normal range $(\mathrm{R}$ wave amplitude $>12.0 \mathrm{mV}$, pacing threshold $1.0 \mathrm{~V}$ at $0.5 \mathrm{~ms}$, and $\mathrm{RV}$ channel impedance $360 \mathrm{ohms}$ ). We compared his event electrogram with the electrocardiogram in sinus rhythm, and found that the short R-R interval during the event was similar to the PR interval (180 ms) (Figure 1B). Chest X-ray confirmed the dislodged lead at the level of the tricuspid annulus (Figure 2A). The lead was repositioned and was found to be intact, with some impacted cardiac tissue at the screw tip (Figure 2B). After repositioning, the patient was followed up regularly without further inappropriate shocks.

\section{Discussion}

Despite the proven survival benefit of ICD therapy, inappropriate shocks can result in adverse events including proarrhythmias, psychiatric disturbances, impaired quality of life, and even death. ${ }^{1-4}$ Inappropriate ICD discharges may result from incorrect detection of supraventricular tachycardia or oversensing of T-waves or non-physiologic signals. ${ }^{3}$ Lead failure is another mechanism, and may cause fatal complications. ${ }^{3,5}$ These complications may be preceded by a change in impedance, threshold, or unexpected noise sensing. Veltmann et al. reported a fatal ICD shock case, in which a loss of R-wave amplitude and decreased lead impedance were observed a few days before the fatal event. ${ }^{3}$

However, in this case, ICD interrogation parameters were within normal range. We later performed simulation testing to determine whether a lead detached from the ventricle could show normal interrogation parameters. We found that all parameters could be within normal range, depending on the lead contact with the endomyocardial wall, especially when the lead screw was loose. Based on this case and our experiences, interrogation parameters

A

B
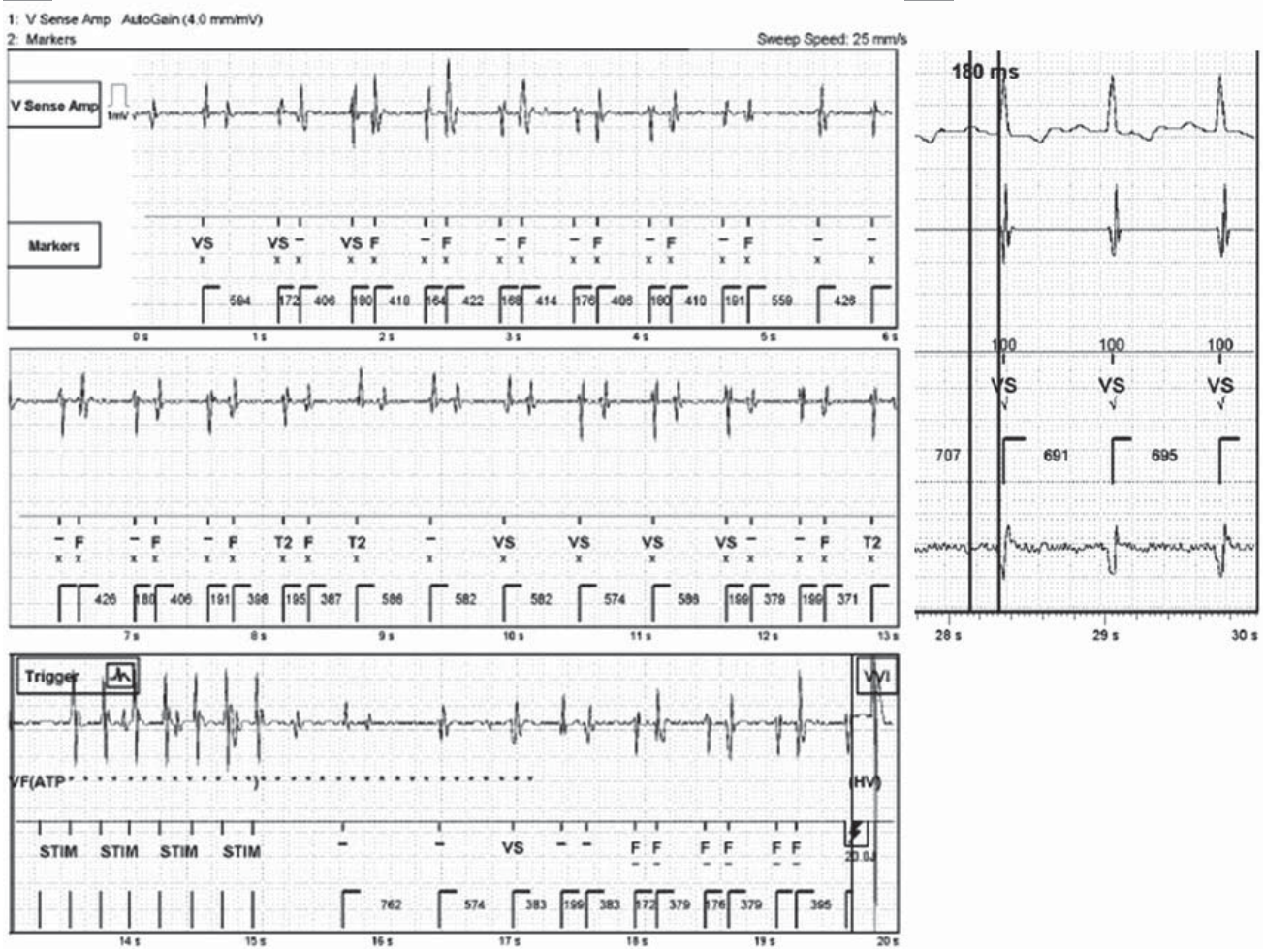

Figure 1. Intracardiac electrogram of the ICD lead during the ICD shock. (A) The upper part was ventricular sensing and the lower part was markers. This episode showed repeated short-long R-R sequence and miscounted short coupled $R$ waves as fibrillation rhythm. (B) PR interval during sinus rhythm was $180 \mathrm{~ms}$, which was compatible with the short R-R interval during the event.

ICD, implantable cardioverter defibrillator 


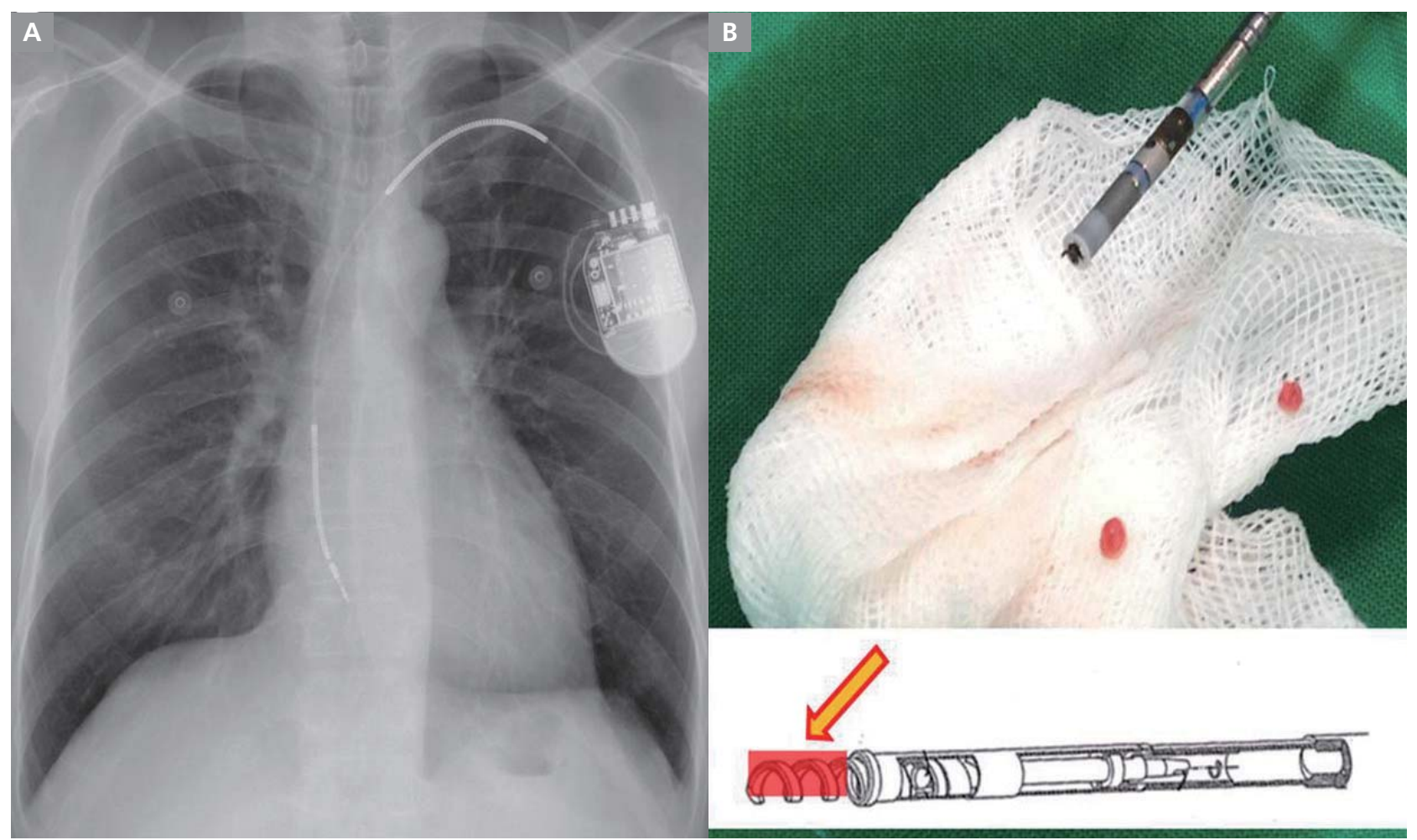

Figure 2. (A) Chest X-ray showed the implanted lead was dislodged to the level of the tricuspid annulus. (B) Extracted lead tip and impacted cardiac tissues.

for the ventricular ICD lead could serve as adjunctive indicators for evaluation of the lead status. A T-wave avoiding algorithm was not effective in our case, because the device diagnosed the rhythm as VF when the detection criteria (12 cumulative intervals) had been fulfilled, even when the device filtered smaller $\mathrm{R}$ waves with associated $\mathrm{T}$ waves in some segments.

In the present case, misreading of atrial signals as ventricular signals by the dislodged lead was the cause of inappropriate shocks. The ICD interrogation parameters were usually within normal range and without any unexpected noise. Although the short-long $\mathrm{R}-\mathrm{R}$ sequence is a common feature of $\mathrm{T}$-wave oversensing, the dislodged lead in our case showed the same pattern. Confirmation of the lead location using a chest X-ray with immediate interrogation of the ICD event is crucial for preventing improper ICD shocks, especially during the first few months after ICD implantation.

\section{Conflict of interest}

The authors have no conflicts of interest to disclosure.

\section{References}

1) Madhavan M, Friedman PA. Optimal programming of implantable cardiac-defibrillators. Circulation. 2013;128:659-672.

2) van Rees JB, Borleffs CJ, de Bie MK, Stijnen T, van Erven L, Bax JJ, Schalij MJ. Inappropriate implantable cardioverter-defibrillator shocks: incidence, predictors, and impact on mortality. J Am Coll Cardiol.2011;57:556-562.

3) Veltmann C, Borggrefe M, Schimpf R, Wolpert C. Fatal inappropriate ICD shock. J Cardiovasc Electrophysiol. 2007;18:326-328.

4) Daubert JP, Zareba W, Cannom DS, McNitt S, Rosero SZ, Wang P, Schuger C, Steinberg JS, Higgins SL, Wilber DJ, Klein H, Andrews ML, Hall WJ, Moss AJ, MADIT II Investigators. Inappropriate implantable cardioverter-defibrillator shocks in MADIT II: frequency, mechanisms, predictors, and survival impact. J Am Coll Cardiol. 2008;51:1357-1365.

5) Messali A, Thomas O, Chauvin M, Coumel P, Leenhardt A. Death due to an implantable cardioverter defibrillator. $J$ Cardiovasc Electrophysiol. 2004;15:953-956. 